\section{(6) OPEN ACCESS}

\title{
Faecal haemoglobin and faecal calprotectin as indicators of bowel disease in patients presenting to primary care with bowel symptoms
}

\author{
Craig Mowat, ${ }^{1}$ Jayne Digby, ${ }^{2}$ Judith A Strachan, ${ }^{3}$ Robyn Wilson, ${ }^{3}$ Francis A Carey, ${ }^{4}$ \\ Callum G Fraser, ${ }^{2}$ Robert J C Steele ${ }^{2}$
}

\begin{abstract}
${ }^{1}$ Department of Gastroenterology, Ninewells Hospital \& Medical School, Dundee, UK

${ }^{2}$ Centre for Research into cancer Prevention and Screening

${ }^{3}$ Department of Blood Sciences, Ninewells Hospital \& Medical School, Dundee, UK ${ }^{4}$ Department of Pathology, Ninewells Hospital \& Medical School, Dundee, UK
\end{abstract}

\section{Correspondence to}

Dr Craig Mowat, Department of Gastroenterology, Ninewells Hospital \& Medical School Dundee DD1 9SY, UK craig.mowat@nhs.net

Received 12 March 2015 Revised 4 June 2015 Accepted 6 June 2015 Published Online First 20 August 2015

\section{CrossMark}

To cite: Mowat C, Digby J, Strachan JA, et al. Gut 2016;65:1463-1469.

\section{ABSTRACT}

Objective In primary care, assessing which patients with bowel symptoms harbour significant disease (cancer, higher-risk adenoma or IBD) is difficult. We studied the diagnostic accuracies of faecal haemoglobin $(\mathrm{FHb})$ and faecal calprotectin (FC) in a cohort of symptomatic patients.

Design From October 2013 to March 2014, general practitioners were prompted to request $\mathrm{FHb}$ and $\mathrm{FC}$ when referring patients with bowel symptoms to secondary care. Faecal samples were analysed for haemoglobin (EIKEN OC-Sensor io) and calprotectin (BÜHLMANN Calprotectin ELISA). Patients triaged to endoscopy were investigated within 6 weeks. All clinicians and endoscopists were blind to the faecal test results. The diagnostic accuracies of FHb and FC for identification of significant bowel disease were assessed. Results 1043 patients returned samples. FHb was detectable in $57.6 \%$ (median $0.4 \mu \mathrm{g} / \mathrm{g}, 95 \% \mathrm{Cl} 0.4$ to 0.8 ; range $0-200)$. FC at $50 \mu \mathrm{g} / \mathrm{g}$ or above was present in $60.0 \%$. 755 patients (54.6\% women, median age 64 years (range 16-90, IQR 52-73)) returned samples and completed colonic investigations. 103 patients had significant bowel disease; the negative predictive values of $\mathrm{FHb}$ for colorectal cancer, higher-risk adenoma and IBD were $100 \%, 97.8 \%$ and $98.4 \%$, respectively. Using cut-offs of detectable FHb and/or $200 \mu \mathrm{g} / \mathrm{g}$ FC detected two further cases of IBD, one higher-risk adenoma and no additional cancers.

Conclusions In primary care, undetectable $\mathrm{FHb}$ is a good 'rule-out' test for significant bowel disease and could guide who requires investigation.

\section{INTRODUCTION}

Patients presenting to general practitioners (GPs) describing new bowel symptoms can be difficult to assess. Referral guidelines from the National Institute for Health and Care Excellence (NICE) highlight features that may suggest serious pathology. ${ }^{1}$ These include rectal bleeding, a mass on examination, iron deficiency anaemia, but also nonspecific symptoms such as a persistent change in bowel habit. The latest revision (due for publication in June 2015) concedes that symptoms have a positive predictive value (PPV) for colorectal cancer (CRC) of only 3-4\%. ${ }^{2}$ A detailed review and meta-analysis also concluded that symptoms alone are poor predictors of underlying pathology. ${ }^{3}$ In the absence of any reliable predictor of pathology,

\section{Significance of this study}

What is already known on this subject?

- Faecal haemoglobin (FHb) concentrations rise as the severity of underlying neoplasia increases.

- Faecal immunochemical tests (FIT) for haemoglobin have superseded guaiac faecal occult blood tests (gFOBT) as the recommended initial test in bowel cancer screening programmes.

- Faecal calprotectin (FC) concentrations rise with inflammation and are useful for monitoring IBD in secondary care.

- To date, no studies have examined the utility of simultaneous quantitative estimates of $\mathrm{FHb}$ and FC exclusively in primary care at the point of referral.

\section{What are the new findings?}

- FHb and FC can be measured from a single sample of faeces collected at home.

- Undetectable FHb measured in samples collected in primary care proved a good 'rule-out test' for significant bowel disease; cancer was excluded, and higher-risk adenomas and IBD were rare.

- $\mathrm{FC}$ at $<50 \mu \mathrm{g} / \mathrm{g}$ ruled out IBD but missed cancer and adenomas.

How might it impact on clinical practice in the foreseeable future?

- We have shown that $\mathrm{FHb}$, measured with quantitative FIT, can be used in primary care at the point of referral as a reliable and objective predictor of underlying pathology.

- General practitioners have an objective tool to guide who requires further investigation in secondary care.

patients will continue to be referred to secondary care for investigation. Colonoscopy is the gold standard for detection of significant bowel disease; namely CRC, higher-risk adenoma (HRA, defined as $\geq$ three adenomas or any adenoma $\geq 1 \mathrm{~cm})^{4}$ and IBD. Low-risk adenomas $(<1 \mathrm{~cm})$ harbour a very low risk of CRC and are excluded from this category. ${ }^{5}$

Our health care system serves a population of around 400000 . Each year approximately 4000 patients are referred from primary care for 
assessment of bowel symptoms via a dedicated referral portal, ensuring equity of access and a streamlined booking process. Referrals are triaged by consultant gastroenterologists; $75 \%$ are brought straight to investigation and the remainder seen in outpatient clinics. The percentage of referrals from GPs marked as 'urgent' or 'urgent suspected cancer' consistently runs at 35$40 \%$. However, when patients undergo colonoscopy, the yield of significant bowel disease is low, with local audit revealing CRC in only $2 \%$ and IBD in $5 \%$.

New means of assessing patients in primary care are urgently needed to help GPs determine which patients need rapid investigation and, in turn, ease pressure on secondary care services. Non-invasive faecal tests for blood and inflammation, already established in CRC screening programmes and IBD clinics respectively, may be helpful in this context.

Faecal immunochemical tests (FITs) for haemoglobin $(\mathrm{Hb})$ are specific for intact human $\mathrm{Hb}$ and its early degradation products. ${ }^{6}$ There are two types of FIT available: qualitative (based upon immunochromatography and providing a positive or negative result) or quantitative (based upon latex agglutination immunoturbidimetry and giving a numerical result for the faecal $\mathrm{Hb}$ (FHb) concentration). Quantitative FITs have been recommended over qualitative to remove reader variability, inter-batch variability and to improve the diagnostic accuracy of the test. ${ }^{78}$ However, FITs made by different manufacturers are not identical. ${ }^{9}$ A range of FHb cut-off concentrations have been used for CRC screening programmes $(15-67 \mu \mathrm{g} / \mathrm{g}) .{ }^{10}$ Data from Europe and Israel on quantitative FIT in patients under surveillance suggest high specificity and negative predictive values (NPVs) for CRC. ${ }^{11-13}$ Furthermore, a pilot study performed by our group has suggested that low $\mathrm{FHb}$ may be a good rule-out test for significant bowel disease in patients referred from primary care. $^{14}$

Faecal calprotectin (FC) has been measured in healthy children and adults but is also a biomarker of inflammation; it is stable at room temperature, homogeneously distributed within faeces and correlates well with faecal excretion of indium ${ }^{111}$-labelled neutrophil granulocytes-the gold standard measure of gut inflammation. ${ }^{15} 16$ It can be analysed by qualitative point-of-care immunochromatographic tests and quantitative ELISA tests. Commonly available assays use a FC cut-off of $50 \mu \mathrm{g} / \mathrm{g}$. FC has a role in the assessment of suspected IBD and in the monitoring of patients with known IBD in secondary and tertiary hospital clinics. ${ }^{15}{ }^{17}$ NICE recommends that FC tests should be available for GPs while acknowledging that further research is required. ${ }^{18}$

In this study, our aim was to study the diagnostic accuracies of quantitative $\mathrm{FHb}$ and $\mathrm{FC}$ tests in patients presenting to primary care with bowel symptoms.

\section{METHODS}

This prospective study gained the full support of GPs and was conducted following the STAndards for the Reporting of Diagnostic accuracy studies guidelines. ${ }^{19}$ All adult patients referred for investigation of bowel symptoms over a 6-month period from October 2013 to March 2014 were eligible. At the point of referring patients to the colorectal pathway, GPs were prompted to request $\mathrm{FHb}$ and $\mathrm{FC}$ tests alongside full blood count, urea and electrolytes and $\mathrm{C}$ reactive protein and record the presenting symptoms via the NHS Tayside electronic test requesting software. If patients had more than one presenting symptom, for the purposes of the present analysis they were attributed only one, in order of decreasing clinical importance as follows: rectal bleeding, anaemia, diarrhoea, altered bowel habit, abdominal pain and weight loss. The total number of referrals and the urgency of the referral were recorded on the referral management software. Practice nurses distributed an EIKEN specimen collection device (for the FHb sample), a plain blue-capped faecal container (for the FC sample) and a patient instruction sheet to each participant. Patients were instructed to collect samples from a single faeces for both tests and to return the samples immediately to the GP surgery. The samples were returned at room temperature via the GP surgery routine sample collection service (a daily van courier service) to Blood Sciences, Ninewells Hospital and Medical School, and stored at $4^{\circ} \mathrm{C}(\mathrm{FHb})$ or $-20^{\circ} \mathrm{C}(\mathrm{FC})$ prior to analysis to ensure stability. $\mathrm{FHb}$ measurement was performed using a single OC-Sensor io analyser (Eiken Chemical Co., Tokyo, Japan). Inter-run imprecision was assessed with quality control materials (Eiken) in each run: Co-efficients of Variation (CVs) were $4.6 \%$ at $25 \mu \mathrm{g} / \mathrm{g}$ and $3.9 \%$ at $93 \mu \mathrm{g} / \mathrm{g}$. Any $\mathrm{FHb}$ sample that was reported by the analytical system as a positive numerical result greater than zero $\mu \mathrm{g} / \mathrm{g}$ was considered as a 'detectable FHb'. FC was analysed after sample extraction using the Roche device (Roche Diagnostics, Burgess Hill, UK) using a quantitative ELISA Calprotectin EK-CAL (BÜHLMANN Laboratories, Switzerland) on a Dynex DS2 (Alpha Labs, Eastleigh, UK). Inter-run CVs were $5.3 \%$ at $37 \mu \mathrm{g} / \mathrm{g}$ and $4.7 \%$ at $152 \mu \mathrm{g} / \mathrm{g}$. Samples with results above the upper analytical limits were not diluted and re-assayed but reported as greater than that upper concentration limit. FHb results were converted from the instrument generated $\mathrm{ng} / \mathrm{mL}$ to the internationally recommended unit of $\mu \mathrm{g} / \mathrm{g}$ by multiplying by $0.2 .^{20}$ The laboratory has a total quality management system in place and is accredited to ISO 15189 based standards. Patients referred to endoscopy were investigated within 6 weeks of referral. The endoscopy units participate in the accreditation scheme of the Joint Accreditation Group on GI Endoscopy. Participating clinicians and endoscopists were blind to the faecal test results. All findings were recorded on the endoscopy reporting system by the endoscopist. The diagnoses of CRC, HRA and IBD were confirmed following assessment by a gastrointestinal pathologist. Clinical outcomes were collected for all patients who completed the tests, and the diagnostic accuracies of FHb and FC for identification of significant bowel disease were examined. MedCalc statistical software (MedCalc Software, Mariakerke, Belgium) was used for all calculations and to produce distribution plots for both faecal test results.

\section{RESULTS}

In total, 2189 patients were referred for investigation. Also, 1032 (47.1\%) referrals were either 'urgent' or 'urgent suspected cancer'. Of those referred, 1043 patients returned faecal samples; 12 patients were excluded (seven in whom neither faecal sample was suitable for analysis, four who returned samples outside the study period and one patient with known IBD) leaving 1031 patients (47.1\%) who formed the study cohort (figure 1). The prevalence of referred symptoms within this cohort was altered bowel habit (42.7\%), rectal bleeding (33.9\%), diarrhoea (16.8\%), abdominal pain (11.0\%), anaemia $(8.7 \%)$, weight loss $(0.9 \%)$ and a palpable mass $(0.3 \%)$. Eight patients submitted FHb samples that were spoiled or unsuitable for analysis. Thirty-nine patients returned FC samples that were classed as insufficient or unsuitable for analysis. FHb was detectable in $57.6 \%$ of all samples submitted (median $0.4 \mu \mathrm{g} / \mathrm{g}, 95 \%$ CI 0.4 to 0.8 ; range 0 to $>200 \mu \mathrm{g} / \mathrm{g}$ ). Using a $\mathrm{FHb}$ cut-off of $10 \mu \mathrm{g} / \mathrm{g}$, the test was positive in $25.2 \%$ of samples. FC $>50 \mu \mathrm{g} /$ $\mathrm{g}$ was present in $60.0 \%$ of all faecal samples (median $69 \mu \mathrm{g} / \mathrm{g}$; range 10 to $>600 \mu \mathrm{g} / \mathrm{g})$. 
Figure 1 Study flow diagram. CRC, colorectal cancer; GP, general practitioner; HRA, higher-risk adenoma.

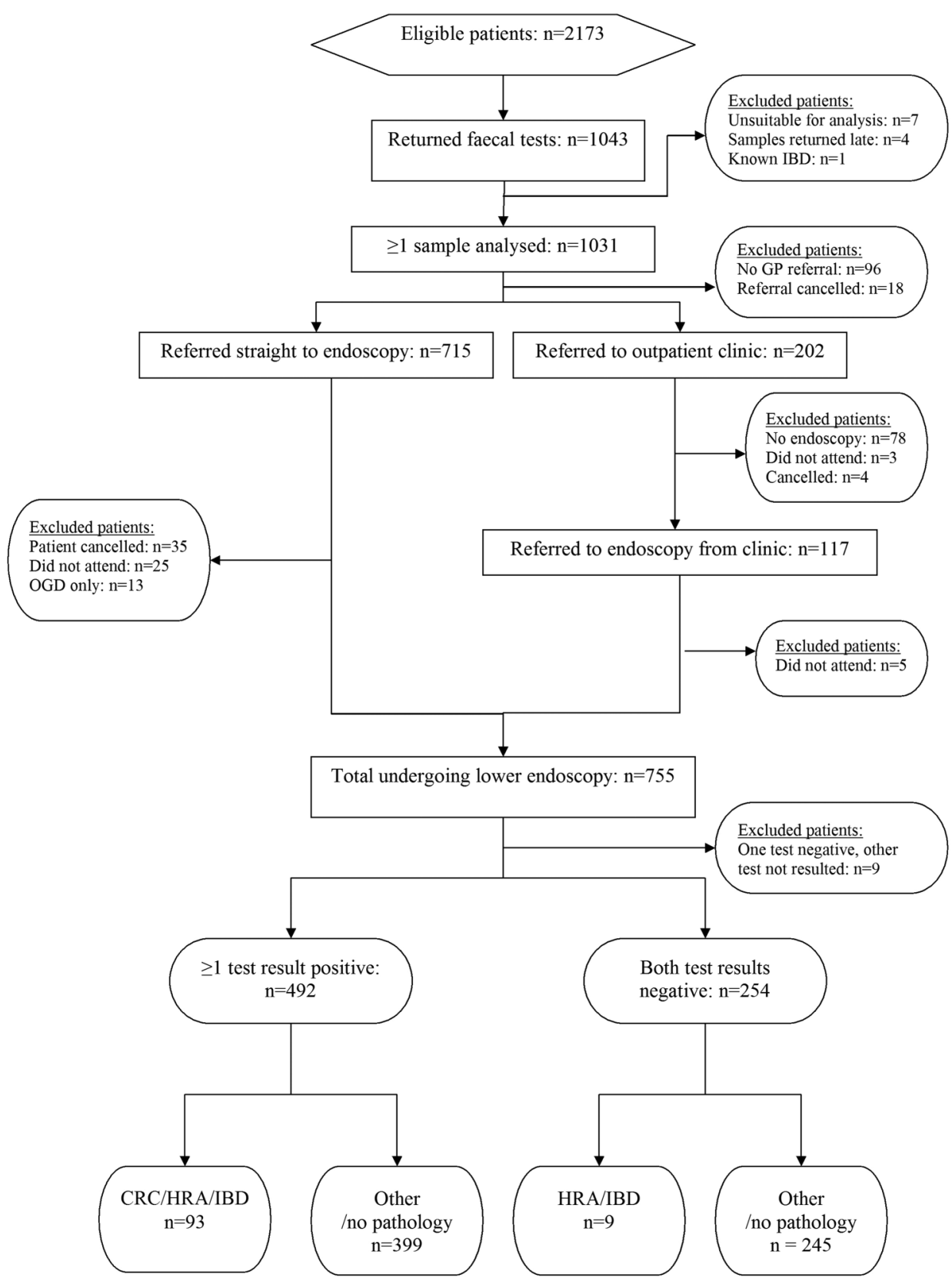

Faecal test performance

The advantage of using quantitative assays is that cut-off concentrations that trigger a positive test result can be altered to regulate positivity rates and diagnostic accuracy (table 2).

Selecting a cut-off of detectable $\mathrm{FHb}$, the positivity rate in those completing investigations was 58.3\%. The PPV for any significant bowel disease was $20.6 \%$. However, the NPV for CRC, HRA and IBD were 100\%, 97.8\% and 98.4\%, respectively: 12 of $102(11.8 \%)$ cases of significant bowel disease had undetectable $\mathrm{FHb}$ (seven HRA, five IBD). Interestingly, 256 of the 755 patients described rectal bleeding, but 87 $(34.0 \%)$ of these had undetectable $\mathrm{FHb}$. In this subgroup, only $3.4 \%$ had significant bowel disease (two with HRA, one with IBD), and the most common finding was haemorrhoids $(38.0 \%)$.

Selecting a FC cut-off of $50 \mu \mathrm{g} / \mathrm{g}$ (often used in differentiating possible IBD from irritable bowel syndrome), the positivity rate was $62.0 \%$. The PPV for any significant bowel disease was $16.9 \%$ and the PPV for IBD was $6.4 \%$. On the other hand, the NPV for IBD was 98.9\%. However, 25 cases of significant patients with CRC had FHb below $10 \mu \mathrm{g} / \mathrm{g}$. The prediction of significant bowel disease was therefore based on the finding of any detectable FHb. 
Table 1 Symptom prevalence and positive predictive values for colorectal cancer (CRC), higher- risk adenoma (HRA) and IBD in patients referred from primary care who were investigated for bowel symptoms $(n=755)$

\begin{tabular}{|c|c|c|c|c|c|c|c|c|c|c|}
\hline & \multicolumn{2}{|c|}{ Total } & \multicolumn{2}{|c|}{ CRC } & \multicolumn{2}{|c|}{ HRA } & \multicolumn{2}{|c|}{ IBD } & \multicolumn{2}{|c|}{$\mathrm{CRC}+\mathrm{HRA}+\mathrm{IBD}$} \\
\hline & $\mathrm{n}$ & $\%$ & $\mathbf{n}$ & $\%$ & $\mathrm{n}$ & $\%$ & $\mathrm{n}$ & $\%$ & $\mathbf{n}$ & $\%$ \\
\hline \multicolumn{11}{|l|}{ Prevalence of symptoms } \\
\hline Altered bowel habit & 323 & 42.8 & 7 & 25.0 & 13 & 31.7 & 7 & 20.6 & 27 & 26.2 \\
\hline Rectal bleeding & 258 & 34.2 & 11 & 39.3 & 20 & 48.8 & 23 & 67.6 & 54 & 52.4 \\
\hline Diarrhoea & 127 & 16.8 & 3 & 10.7 & 6 & 14.6 & 9 & 26.5 & 18 & 17.5 \\
\hline Anaemia & 67 & 8.9 & 6 & 21.4 & 2 & 4.9 & 2 & 5.9 & 10 & 9.7 \\
\hline Abdominal pain & 83 & 11.0 & 3 & 10.7 & 5 & 12.2 & 2 & 5.9 & 10 & 9.7 \\
\hline Weight loss & 7 & 0.9 & 1 & 3.6 & 0 & 0.0 & 0 & 0.0 & 1 & 1.0 \\
\hline Mass & 2 & 0.3 & 1 & 3.6 & 0 & 0.0 & 0 & 0.0 & 1 & 1.0 \\
\hline Number of patients & 755 & & 28 & & 41 & & 34 & & 103 & \\
\hline \multicolumn{11}{|l|}{ Positive predictive values } \\
\hline Altered bowel habit & 323 & 42.8 & 7 & 2.2 & 13 & 4.0 & 7 & 2.2 & 27 & 8.4 \\
\hline Rectal bleeding & 258 & 34.2 & 11 & 4.3 & 20 & 7.8 & 23 & 8.9 & 54 & 21.0 \\
\hline Diarrhoea & 127 & 16.8 & 3 & 2.4 & 6 & 4.7 & 9 & 7.1 & 18 & 14.2 \\
\hline Anaemia & 67 & 8.9 & 6 & 9.0 & 2 & 3.0 & 2 & 3.0 & 10 & 15.2 \\
\hline Abdominal pain & 83 & 11.0 & 3 & 3.6 & 5 & 6.0 & 2 & 2.4 & 10 & 12.0 \\
\hline Weight loss & 7 & 0.9 & 1 & 14.3 & 0 & 0.0 & 0 & 0.0 & 1 & 14.3 \\
\hline Mass & 2 & 0.3 & 1 & 50.0 & 0 & 0.0 & 0 & 0.0 & 1 & 50.0 \\
\hline Number of patients & 755 & & 28 & & 41 & & 34 & & 103 & \\
\hline
\end{tabular}

bowel disease had FC below this cut-off (5 CRC, 17 HRA, 3 IBD).

Selecting a combined cut-off of detectable FHb and/or FC at $50 \mu \mathrm{g} / \mathrm{g}$ generated a high positivity rate of $80.5 \%$. The PPV for any significant bowel disease was $16.5 \%$. However, only four cases of significant bowel disease were undetected using this strategy (three HRA, one IBD).

Raising the FC cut-off to an arbitrary $200 \mu \mathrm{g} / \mathrm{g}$, the positivity rate fell to $25.9 \%$, the PPV for IBD increased to $12.2 \%$, yet the NPV for IBD remained at $98.3 \%$. However, more than half of the cases of CRC remained undetected.
Selecting a combined cut-off of detectable $\mathrm{FHb}$ and/or FC $200 \mu \mathrm{g} / \mathrm{g}$ generated a positivity rate of $66.0 \%$. The PPV for any significant bowel disease was $18.9 \%$. At this combined cut-off, the NPV for CRC, HRA, IBD were $100 \%, 97.6 \%$ and $98.8 \%$, respectively. Nine cases of significant bowel disease were undetected (six HRA, three IBD).

\section{DISCUSSION}

This study demonstrates that patients presenting to primary care with bowel symptoms can be assessed with faecal tests and the results can help determine whether further investigation is
Figure 2 Distribution of faecal haemoglobin concentration $(\mathrm{FHb})$ in patient samples collected in primary care according to the results of bowel investigations $(n=1023)$. HRA, higher-risk adenoma

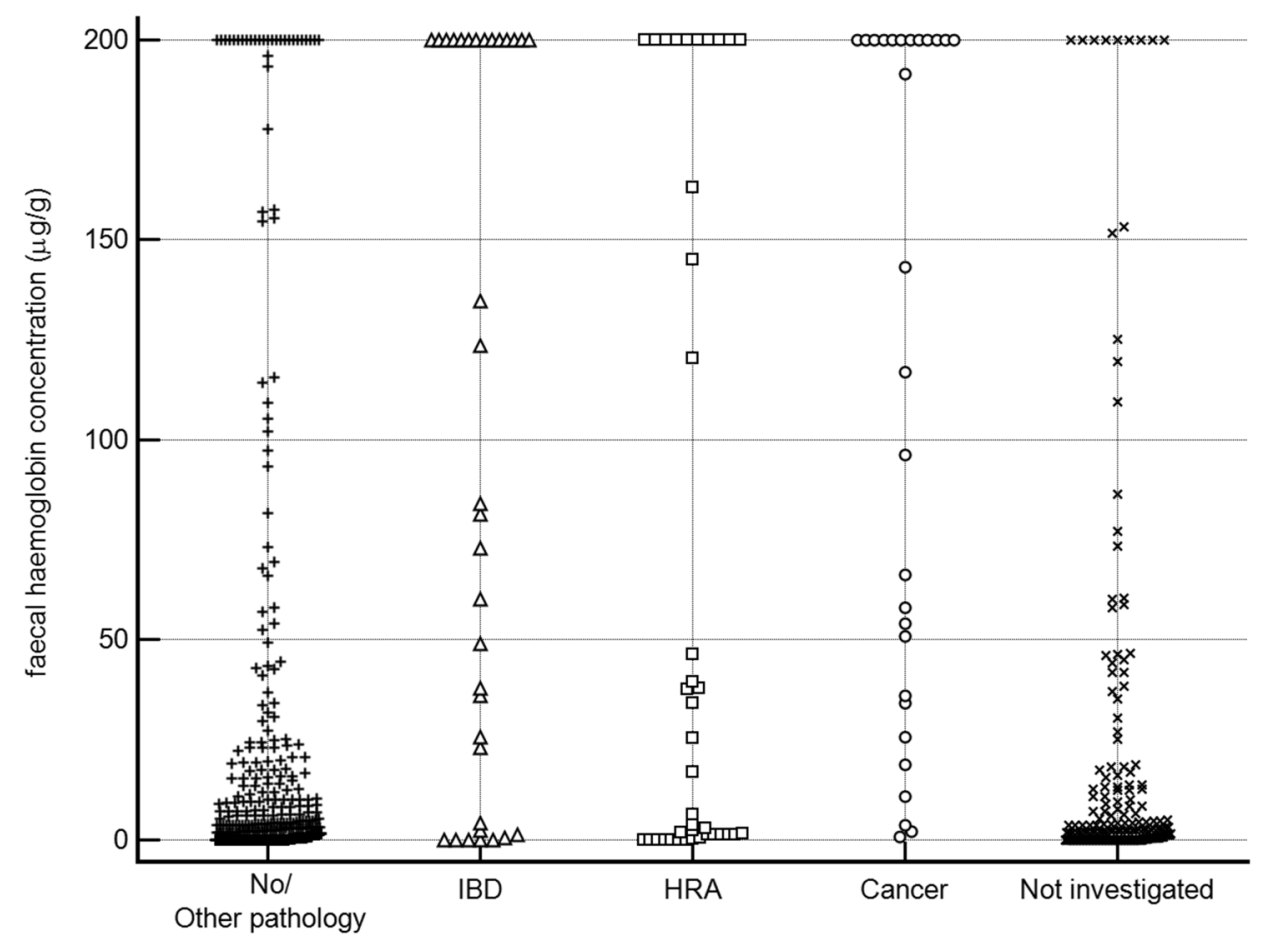


Figure 3 Distribution of faecal calprotectin concentrations in patient samples collected in primary care according to the results of bowel investigations $(n=993)$. HRA, higher-risk adenoma.

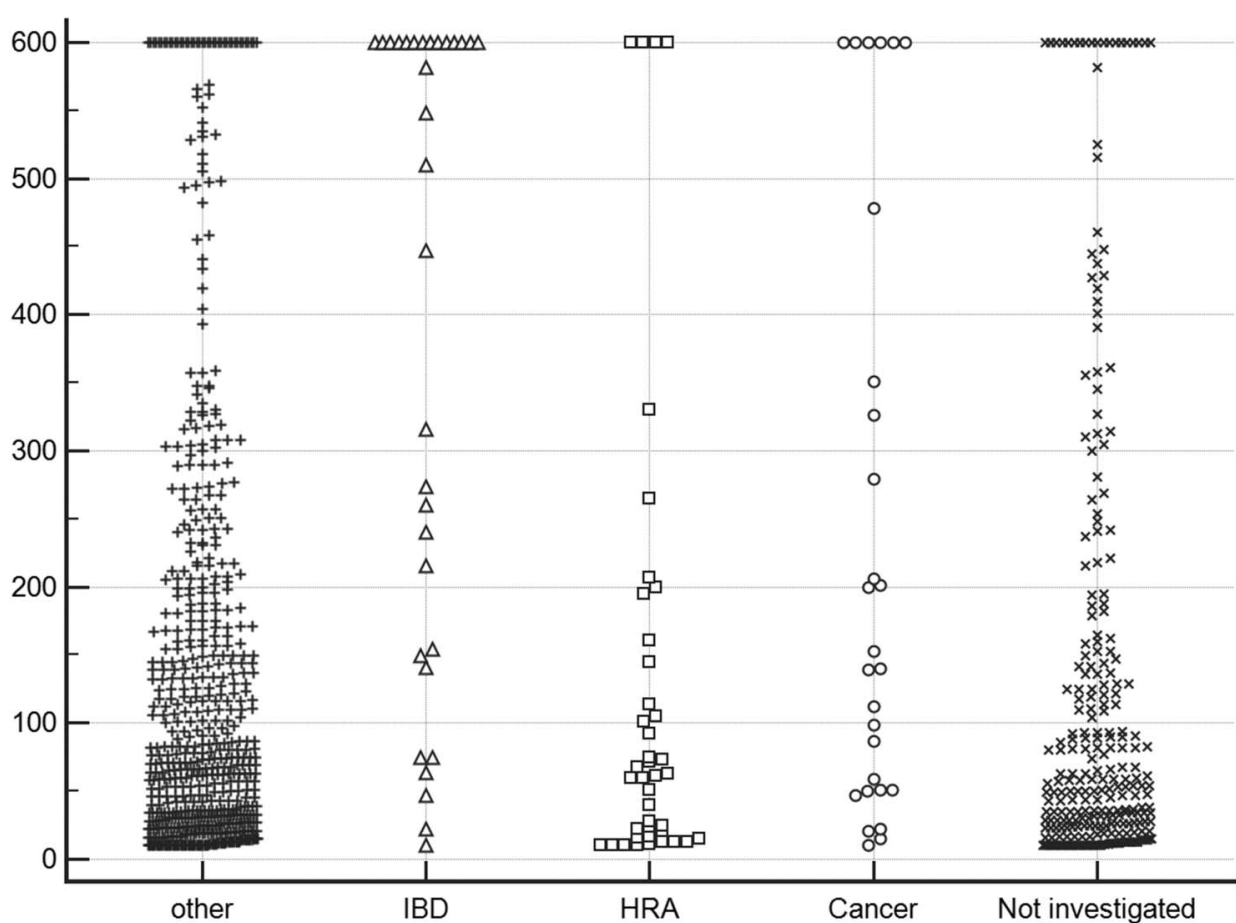

a cut-off of $8 \mu \mathrm{g} / \mathrm{g}$ faeces in the assessment of patients attending a Rapid Access Clinic in secondary care and, although the authors concentrated on the use of this as a rule-in test for CRC, the NPV for CRC was $100 \% .^{26}$

It should be noted that quantitative and qualitative FIT analytical systems do not give identical results, even if the results are reported in the recommended units of $\mu \mathrm{g} / \mathrm{g}:{ }^{20}$ this applies to both qualitative and quantitative FIT. ${ }^{9} 27$ There are a number of plausible reasons for this including difference in the mass of faeces collected, the volume of buffer in the specimen collection device, the stability of $\mathrm{Hb}$ in the device and, probably most importantly, the specificity of the antibodies used to capture the $\mathrm{Hb}$ and early degradation products for subsequent analysis by immunochromatography or immunoturbidimetry. ${ }^{28}$

It is becoming clear from recent studies in CRC screening programmes that there are marked gender differences; it is well established that men have a greater prevalence of colorectal neoplasia, but it is now also clear that men harbour higher concentrations of FHb than women. ${ }^{29}$ We did not design our study to examine gender differences; however, we did note a trend for more significant bowel disease in men (15.5\%) versus women $(11.9 \%)$. Furthermore, with a cut-off of any detectable FHb, the PPVs for CRC, HRA plus IBD were higher in men than women $(22.6 \%$ vs $18.3 \%)$, but there was no difference in NPVs. While there is a cogent argument to consider genderspecific $\mathrm{FHb}$ cut-offs in asymptomatic population bowel screening programmes, gender differences in PPV become irrelevant in a symptomatic patient with detectable $\mathrm{FHb}$ because invasive investigations would be required in all.

The strength of our study is that it was conducted in a single health care organisation in which all referrals from primary care enter through a common referral pathway, removing selection bias. Faecal tests were requested at the point of referral and samples reached the laboratory via a daily delivery van service. The mean ambient temperature in this region of Scotland was never $>16^{\circ} \mathrm{C}$ during the study: therefore, $\mathrm{FHb}$ degradation during transport would be minimal. ${ }^{9}{ }^{30}$ The study cohort appeared to be typical of primary care referrals with $3.7 \%$ risk) adenoma. Adding $\mathrm{FC}$ at $50 \mu \mathrm{g} / \mathrm{g}$ produced an NPV of 94.4\%. Those with IBD were excluded. ${ }^{25}$ A further small study reported the benefit of a point-of-care qualitative $\mathrm{FHb}$ test with 
Table 2 Performance of faecal haemoglobin concentration (FHb) and faecal calprotectin concentration (FC) in the detection of colorectal cancer (CRC), higher-risk adenoma (HRA) and IBD using cut-offs at different concentrations (units: $\mu \mathrm{g} / \mathrm{g})(\mathrm{n}=755)$

\begin{tabular}{|c|c|c|c|c|c|c|}
\hline & $\mathrm{FHb} \geq 10$ & $\mathrm{FC} \geq 50$ & FHb detectable & $\begin{array}{l}\text { FHb detectable } \\
\text { and/or FC } \geq 50\end{array}$ & $\mathrm{FC} \geq \mathbf{2 0 0}$ & $\begin{array}{l}\text { FHb detectable } \\
\text { and/or FC } \geq 200\end{array}$ \\
\hline Positivity rate & $23.5 \%$ & $62.0 \%$ & $58.3 \%$ & $80.5 \%$ & $25.9 \%$ & $66.0 \%$ \\
\hline \multicolumn{7}{|l|}{ CRC $(n=28)$} \\
\hline Number of cases & 28 & 28 & 28 & 28 & 28 & 28 \\
\hline True positives & 25 & 23 & 28 & 28 & 13 & 28 \\
\hline False negatives & 3 & 5 & 0 & 0 & 15 & 0 \\
\hline False positives & 151 & 427 & 409 & 573 & 175 & 464 \\
\hline True negatives & 571 & 271 & 313 & 146 & 523 & 254 \\
\hline PPV & $14.2 \%$ & $5.1 \%$ & $6.4 \%$ & $4.7 \%$ & $6.9 \%$ & $5.7 \%$ \\
\hline NPV & $99.5 \%$ & $98.2 \%$ & $100 \%$ & $100 \%$ & $97.2 \%$ & $100 \%$ \\
\hline Sensitivity & $89.3 \%$ & $82.1 \%$ & $100 \%$ & $100 \%$ & $46.4 \%$ & $100 \%$ \\
\hline Specificity & $79.1 \%$ & $38.8 \%$ & $43.4 \%$ & $20.3 \%$ & $74.9 \%$ & $35.4 \%$ \\
\hline \multicolumn{7}{|l|}{ HRA $(n=41)$} \\
\hline Number of cases & $40^{*}$ & 41 & 40 & 41 & 41 & 40 \\
\hline True positives & 20 & 24 & 33 & 38 & 8 & 34 \\
\hline False negatives & 20 & 17 & 7 & 3 & 33 & 6 \\
\hline False positives & 156 & 426 & 404 & 563 & 180 & 458 \\
\hline True negatives & 554 & 259 & 306 & 143 & 505 & 248 \\
\hline PPV & $11.4 \%$ & $5.3 \%$ & $7.6 \%$ & $6.3 \%$ & $4.3 \%$ & $6.9 \%$ \\
\hline NPV & $96.5 \%$ & $93.8 \%$ & $97.8 \%$ & $97.9 \%$ & $93.8 \%$ & $97.6 \%$ \\
\hline Sensitivity & $50.0 \%$ & $58.5 \%$ & $82.5 \%$ & $92.7 \%$ & $19.5 \%$ & $85.0 \%$ \\
\hline Specificity & $78.0 \%$ & $37.8 \%$ & $43.1 \%$ & $20.3 \%$ & $73.7 \%$ & $35.1 \%$ \\
\hline \multicolumn{7}{|l|}{ IBD $(n=34)$} \\
\hline Number of cases & 34 & $32^{*}$ & 34 & 34 & 32 & 34 \\
\hline True positives & 25 & 29 & 29 & 33 & 23 & 31 \\
\hline False negatives & 9 & 3 & 5 & 1 & 9 & 3 \\
\hline False positives & 151 & 421 & 408 & 568 & 165 & 461 \\
\hline True negatives & 565 & 273 & 308 & 145 & 529 & 251 \\
\hline PPV & $14.2 \%$ & $6.4 \%$ & $6.7 \%$ & $5.5 \%$ & $12.2 \%$ & $6.3 \%$ \\
\hline NPV & $98.4 \%$ & $98.9 \%$ & $98.4 \%$ & $99.3 \%$ & $98.3 \%$ & $98.8 \%$ \\
\hline Sensitivity & $73.5 \%$ & $90.6 \%$ & $85.3 \%$ & $97.1 \%$ & $71.9 \%$ & $91.2 \%$ \\
\hline Specificity & $78.9 \%$ & $39.3 \%$ & $43.0 \%$ & $20.3 \%$ & $76.2 \%$ & $35.3 \%$ \\
\hline \multicolumn{7}{|l|}{$\mathrm{CRC}+\mathrm{HRA}+\mathrm{IBD}$} \\
\hline Number of cases & 102 & $101^{*}$ & 102 & 103 & 101 & 102 \\
\hline True positives & 70 & 76 & 90 & 99 & 44 & 93 \\
\hline False negatives & 32 & 25 & 12 & 4 & 57 & 9 \\
\hline False positives & 106 & 374 & 347 & 502 & 144 & 399 \\
\hline True negatives & 542 & 251 & 301 & 142 & 481 & 245 \\
\hline PPV & $39.8 \%$ & $16.9 \%$ & $20.6 \%$ & $16.5 \%$ & $23.4 \%$ & $18.9 \%$ \\
\hline NPV & $94.4 \%$ & $90.9 \%$ & $96.2 \%$ & $97.3 \%$ & $89.4 \%$ & $96.5 \%$ \\
\hline Sensitivity & $68.6 \%$ & $75.2 \%$ & $88.2 \%$ & $96.1 \%$ & $43.6 \%$ & $91.2 \%$ \\
\hline Specificity & $83.6 \%$ & $40.2 \%$ & $46.4 \%$ & $22.0 \%$ & $77.0 \%$ & $38.0 \%$ \\
\hline
\end{tabular}

${ }^{*}$ One case of HRA had FHb sample unsuitable for analysis. Two cases of IBD had FC samples unsuitable for analysis.

NPV, negative predictive value.

having underlying CRC, and rectal bleeding having a PPV of 4.3\% for CRC.

In population screening and in IBD clinics, FHb and FC cut-offs have been proposed. With symptomatic patients in primary care for whom the underlying diagnosis remains to be determined, we could not anticipate what the appropriate cut-off concentrations might be. We noted three cases of CRC in this cohort in whom $\mathrm{FHb}$ fell below the $10 \mu \mathrm{g} / \mathrm{g}$ cut-off concentration commonly used in CRC screening programmes and qualitative FIT. In consequence, we chose a cut-off of any detectable $\mathrm{FHb}$ for test performance analysis since no cases of CRC would be missed. When faced with a symptomatic patient, an undetectable $\mathrm{FHb}$ would reassure a GP that significant bowel disease would be rare. With FC at the widely used cut-off of $50 \mu \mathrm{g} / \mathrm{g}$, this proved to be an effective 'rule-out' test for IBD, but would miss almost a fifth of CRC cases. This would not reassure GPs or patients. If FC is combined with $\mathrm{FHb}$, only one case of IBD was missed, but the vast majority of patients would have a positive test $(80.5 \%)$ and require further investigation. Raising the FC cut-off to $200 \mu \mathrm{g} / \mathrm{g}$, combined with detectable $\mathrm{FHb}$, dropped the combined positivity rate to a manageable $66.0 \%$. However, only three more cases of significant but nonmalignant bowel disease were detected at the expense of investigating 7.7\% more referrals than using $\mathrm{FHb}$ alone.

At present, in the absence of any reliable predictor of pathology, the vast majority of referrals from primary care for 
assessment of colorectal symptoms undergo invasive investigations but the yield of pathology is low. This study demonstrates that $\mathrm{FHb}$ and FC can provide objective information on the likelihood of significant underlying pathology but cannot replace common sense. Patients with anaemia or a mass require investigation irrespective of faecal test results. However, $34.0 \%$ with rectal bleeding had undetectable $\mathrm{FHb}$; upon investigation haemorrhoids were the most common finding and the incidence of significant bowel disease was only $3.4 \%$. Based on our findings, patients presenting to primary care with bowel symptoms could be tested with $\mathrm{FHb}$ and FC in the knowledge that approximately one-third of patients who would normally be referred for investigation will have negative test results and do not require immediate invasive investigations. In our health care organisation, this translates into almost 1200 patients per year who are highly likely to have no significant bowel disease and do not require immediate investigation. If $\mathrm{FHb}$ was the sole faecal test, that figure would rise to almost 1400. Moreover, using one only test has advantages since FIT specimen collection devices are more user-friendly, $\mathrm{FHb}$ is cheaper to analyse and has a more rapid turnaround time.

In summary, this study demonstrates that non-invasive faecal tests requested in primary care provide a reliable prediction of the absence of significant bowel disease. FHb is superior to FC and enables, with a single faecal test, an objective assessment of the need and urgency of further investigation.

Acknowledgements lain McElarney of MAST Group (http://www.mastgrp.com) helped in the design and production of the patient information sheets. Lynne Taylor, NHS Tayside Blood Sciences, distributed faecal test packs to GP practices and logged specimens on return. Paula McDonald, Laboratory Team Leader, Scottish Bowel Screening Centre, provided technical assistance with the EIKEN io analyser.

Contributors CM, JAS and RJCS designed, planned and conducted the study. RW analysed the faecal samples. JD performed the statistical analysis and produced the figures and tables. All authors contributed to data interpretation and writing of the paper. CM wrote the final draft, which was approved by all authors.

Funding The study was funded by the Detect Cancer Early initiative of the Scottish Government. JD was supported by a grant from Tenovus.

Competing interests CGF has undertaken consultancy with Immunostics, Ocean, New Jersey, USA; Mode Diagnostics, Glasgow, Scotland; and Kyowa-Medex Co., Tokyo, Japan: and has received travel support from Alpha Labs, Eastleigh, UK.

Ethics approval East of Scotland REC.

Provenance and peer review Not commissioned; externally peer reviewed.

Open Access This is an Open Access article distributed in accordance with the Creative Commons Attribution Non Commercial (CC BY-NC 4.0) license, which permits others to distribute, remix, adapt, build upon this work non-commercially, and license their derivative works on different terms, provided the original work is properly cited and the use is non-commercial. See: http://creativecommons.org/ licenses/by-nc/4.0/

\section{REFERENCES}

$1 \quad$ NICE clinical guideline 27; Referral guidelines for suspected cancer. http://www.nice. org.uk/guidance/cg27/resources/guidance-referral-guidelines-for-suspected-cancerpdf (accessed May 2015).

2 NICE guideline; Suspected cancer: recognition and management of suspected cancer in children, young people and adults. http://www.nice.org.uk/guidance/ indevelopment/gid-cgwave0618 (accessed May 2015).

3 Jellema $\mathrm{P}$, van der Windt DAWM, Bruinvels DA, et al. Value of symptoms and additional diagnostic tests for colorectal cancer in primary care; systematic review and meta-analysis. BMJ 2010:340:c1269.

4 Lieberman DA, Rex DK, Winawer SJ, et al. Guidelines for colonoscopy surveillance after screening and polypectomy: a consensus update by the US Multi-Society Task Force on colorectal cancer. Gastroenterology 2012;143:844-57.

5 Atkin WS, Morson BC, Cuzick J. Long-term risk of CRC after excision of rectosigmoid adenomas. NEJM 1992;326:658-62.
6 Allison JE, Fraser CG, Halloran SP, et al. Population screening for colorectal cancer means getting FIT: the past, present and future of colorectal cancer screening using the Fecal Immunochemical Test for Hemoglobin (FIT). Gut Liver 2014;8:117-30.

7 Duffy MJ, van Rossum LGM, van Turenhout ST, et al. Use of faecal markers in screening for colorectal neoplasia: a European Group on Tumour Markers (EGTM) position paper. Int J Cancer 2011;128:3-11.

8 Fraser CG, Allison JE, Young GP, et al. Quantitation of hemoglobin improves fecal immunochemical tests for noninvasive screening. Clin Gastroenterol Hepatol 2013;11:839-40.

9 Young GP, Symonds EL, Allison JE, et al. Advances in fecal occult blood tests: the FIT revolution. Dig Dis Sci 2015;60;609-22.

10 Chiang TH, Chuang SL, Chen SL, et al. Difference in performance of fecal immunochemical tests with the same hemoglobin cutoff concentration in a nationwide colorectal cancer screening program. Gastroenterology 2014;147:1317-26.

11 Hazazi R, Rozen $P$, Leshno $M$, et al. Can patients at high risk for significant colorectal neoplasms and having normal quantitative faecal occult blood test postpone elective colonoscopy? Aliment Pharmacol Ther 2010;31:523-33.

12 Terhaar sive Droste JS, van Turenhout ST, Oort FA, et al. Faecal Immunochemical test accuracy in patients referred for surveillance colonoscopy: a multi-centre cohort study. BMC Gastroenterol 2012;12:94.

13 Castro I, Cubiella J, Rivera $C$, et al. Faecal Immunochemical test accuracy in familial risk colorectal cancer screening. Int J Cancer 2014;134:367-75.

14 McDonald PJ, Digby J, Innes C, et al. Low faecal haemoglobin concentration potentially rules out significant colorectal disease. Colorectal Dis 2013;15:e151-9.

15 Sipponen T. Diagnostics and prognostics of inflammatory bowel disease with fecal neutrophil-derived biomarkers calprotectin and lactoferrin. Dig Dis 2013;31:336-44

16 Roseth AG, Schmidt PN, Fagerhol MK. Correlation between faecal excretion of Indium-111-labelled granulocytes and calprotectin, a granulocyte market protein, in patients with inflammatory bowel disease. Scand J Gastroenterol 1999:34:50-4.

17 van Rheenen PF, Van de Vijver E, Fidler V. Faecal calprotectin for screening of patients with suspected inflammatory bowel disease: diagnostic meta-analysis. BMJ 2010;341:c3369.

18 NICE Diagnostics guidance (DG11). Faecal calprotectin diagnostic tests for inflammatory diseases of the bowel. https://www.nice.org.uk/guidance/dg11 (accessed Dec 2014)

19 Standards for the reporting of diagnostic accuracy studies. http://www.stardstatement.org/ (last accessed December 2014)

20 Fraser CG, Allison JE, Halloran SP, et al. A proposal to standardize reporting units for fecal immunochemical tests for hemoglobin. J Natl Cancer Inst 2012;104:610-14.

21 Pavlidis P, Chedgy FJQ, Tibble JA. Diagnostic accuracy and clinical application of faecal calprotectin in adult patients presenting with gastrointestinal symptoms in primary care. Scand J Gastroenterol 2013;48:1048-54.

22 Högberg C, Karling $\mathrm{P}$, Rutegård J, et al. Immunochemical faecal occult blood tests in primary care and the risk of delay in the diagnosis of colorectal cancer. Scand J Prim Health Care 2013;31;209-14.

23 Kok L, Elias SG, Witteman BJ, et al. Diagnostic accuracy of point-of-care fecal calprotectin and immunochemical occult blood tests for diagnosis of organic bowel disease in primary care: the Cost-Effectiveness of a Decision Rule for Abdominal Complaints in Primary Care (CEDAR) study. Clin Chem 2012;58:989-8.

24 Cubiella J, Salve M, Díaz-Ondina M, et al. Diagnostic accuracy of the faecal immunochemical test for colorectal cancer in symptomatic patients; comparison with NICE and SIGN referral criteria. Colorectal Dis 2014;16:0273-82.

25 Parente F, Marino B, llardo A, et al. A combination of faecal tests for the detection of colon cancer: a new strategy for an appropriate selection of referrals to colonoscopy? A prospective multicentre Italian study. Eur J Gastroenterol Hepatol 2012:24:1145-52.

26 Kaul A, Shah A, Magill FH, et al. Immunological faecal occult blood testing: a discriminatory test to identify colorectal cancer in symptomatic patients. Int I Surg 2013;11;329-31.

27 Allison JE, Fraser CG, Halloran SP, et al. Comparing fecal immunochemical tests: improved standardization is needed. Gastroenterology 2012;142:422-4.

28 Rapi S, Rubeca T, Fraser CG. How to improve the performances of Fecal Immunological Tests (FIT): Need for standardization of the sampling and preanalytical phases and revision of the procedures for comparison of methods. Int J Biol Markers 2015;30:e127-31.

29 McDonald PJ, Strachan JA, Digby J, et al. Faecal haemoglobin concentrations by gender and age: implications for population-based screening for colorectal cancer. Clin Chem Lab Med 2012:50:935-40.

30 WeatherSpark Beautiful weather graphs and maps. https://weatherspark.com/\#! dashboard;ws=28758 (accessed Mar 2015). 